\title{
A Model on Knowledge and Endogenous Growth
}

\author{
Derek H. C. Chen* and Hiau Looi Kee**
}

\author{
The World Bank \\ Washington DC 20433
}

\begin{abstract}
This paper presents a model of endogenous growth in which the main engine of economic development is knowledge. Using a two-sector closed economy model that comprises of a conventional goods-producing sector and a research and development sector, our model incorporates two key aspects of knowledge: technology and human capital. Steady-state equilibrium conditions show that the growth rate of per capita income hinges on the growth rate of human capital. While the growth rate of human capital has been previously shown to affect the growth of the economy in transition between steady states or balanced growth paths, this paper is the first to link the growth rate of human capital to the steady-state growth rate of productivity and output per worker. Furthermore, this result does not exhibit scale effects or policy invariance, both of which have been longstanding concerns with the predictions of endogenous growth models developed in the 1990s.
\end{abstract}

\section{World Bank Policy Research Working Paper 3539, March 2005}

The Policy Research Working Paper Series disseminates the findings of work in progress to encourage the exchange of ideas about development issues. An objective of the series is to get the findings out quickly, even if the presentations are less than fully polished. The papers carry the names of the authors and should be cited accordingly. The findings, interpretations, and conclusions expressed in this paper are entirely those of the authors. They do not necessarily represent the view of the World Bank, its Executive Directors, or the countries they represent. Policy Research Working Papers are available online at http:/lecon.worldbank.org.

* The Knowledge for Development Program, World Bank Institute. ** International Trade Team, Development Research Group. 


\section{Table of Contents}

\section{Introduction}

\section{Theoretical Model}

2.1 Derivation of the Steady-State Condition for Capital Accumulation

2.2 Derivation of the Steady-State Condition for Technological Growth

2.3 Derivation of the Steady-State Solution

2.4 Effect of Growth of Human Capital on Steady-State Technological Growth

2.5 Derivation of Steady-State Output Growth

\section{Policy Exercises}

3.1 An Increase in the Growth Rate of Human Capital

3.2 An Improvement in the ICT Infrastructure

\section{Summary and Conclusion}

\section{References}

\section{Figures}




\section{Introduction}

Early endogenous growth models, such as Romer (1990), Grossman and Helpman (1991), and Aghion and Howitt (1992), attempt to explain productivity growth by the introduction of a research and development (R\&D) sector, with human capital or skilled labor as an input. These models show that the steady-state growth rate of output per worker depends positively on the level of available resources for R\&D in the economy, such as the stock of human capital or endowment of skilled labor. Hence, an increase in the average educational attainment of the labor force, for example, will lead to a permanent increase in the long-term growth rate of per capita income. The literature refers to these effects, where the level of resources influences the long-term growth rate, as scale effects (see Jones, 1999).

Many researchers have pointed out that such scale effects fail to reflect reality. The high growth rates of the East Asian Newly Industrializing Economies (NIEs), which averaged 8 percent annually for the past three decades despite initial low levels of human capital stocks, as compared to the 2 percent exhibited by the developed countries, provide an excellent counter example.

Subsequent R\&D-based growth models have attempted to eliminate this prediction. For example, Jones (1995), Kortum (1997) and Segerstrom (1998) develop models in which the growth rate of per capita income depends only on parameters that are usually taken as exogenous, such as the growth rate of population, and no longer depends on the level of R\&D resources in the economy. In such models, levels of human capital and other $R \& D$ resources affect only the long-run level of per capita income, but not the growth rate.

While the predictions of the latter class of models certainly do not preclude the experience of the NIEs, they imply the growth rate of per capita income is, to a large extent, invariant to government policies. Hence, policies such as tax incentives for R\&D or education subsidies, which are commonly accepted to promote technical progress and hence long-term economic growth, will have no effect on the steady-state growth rate of per capita income. In short, these predictions are at odds with conventional wisdom.

In this paper, we develop a theoretical model of endogenous growth in which knowledge is the main engine of economic development. Similar to the models mentioned above, apart from the conventional goods-producing sector, an R\&D sector is introduced to endogenize the accumulation of knowledge via technical progress, which is the underlying source of long-term growth in per capita income. As in Romer (1990), we re-emphasize the explicit role of human capital as an input into both sectors. 
We show that in our model with human capital as a factor of production, the steady-state growth rate of per capita income depends positively on the growth rate of human capital. While the growth rate of human capital has been previously shown to affect the growth of the economy in transition between steady states or balanced growth paths, this paper is the first to link the growth rate of human capital to the steady-state growth rate of productivity and output per worker.

Furthermore, we note that scale effects, where the steady-state growth rate is dependent on the level of $R \& D$ resources or the stock of human capital, are absent from our model. In addition, given that the growth rate of human capital is a determinant of the steady-state growth rate of per capita income, the prediction of this model provides a channel through which government policies can influence the long-term growth rate. This paper therefore provides an important contribution to the literature as it demonstrates that relatively simple neoclassical models with human capital as a factor of production are able to resolve the concerns of scale effects and policy invariance that characterize the predictions of the two classes of models discussed above. ${ }^{1}$

The paper also proceeds to examine the steady-state effects of two scenarios that could result from common development-oriented policies. The first considers an exogenous increase in the rate of human capital accumulation, while the second assumes a one-time exogenous increase or improvement in the economy's information and communications technology (ICT) infrastructure. Both exercises show that even onetime positive shocks can have long-run positive effects on technological growth, capital accumulation and economic development.

This paper is laid out as follows. Section 2 derives the two-sector model. Section 3 illustrates the steady-state effects of two policy shocks: an exogenous increase in the growth rate of human capital and an exogenous improvement in the ICT infrastructure. Section 4 presents a summary with the main conclusions.

\footnotetext{
${ }^{1}$ To date, a number of other models have been developed using various methods to resolve problems of scale effects and/or policy invariance in endogenous growth models. For example, see Aghion and Howitt (1998), Dinopoulos and Thompson (1998), Howitt and Aghion (1998), Peretto (1998), Young (1998), Segerstrom (2000), and Lloyd-Ellis and Roberts (2002).
} 


\section{Theoretical Model}

The following model draws on a model derived in Romer (1996).

We first assume that the economy comprises of two sectors: a goods-producing sector and an R\&D sector. The former produces conventional output, while the latter produces new technology, which adds to the existing level of technology. As mentioned above, factors of production in the economy, namely, capital $(K)$, labor $(L)$ and human capital $(H)$ are allocated for use either in the goods or R\&D sector.

\section{Let \\ $a_{K} \quad$ be the fraction of $K_{t}$ used in the R\&D sector \\ $a_{H} \quad$ be the fraction of $H_{t}$ used in the R\&D sector \\ $a_{L} \quad$ be the fraction of $L_{t}$ used in the R\&D sector}

This implies that

$\left(1-a_{K}\right) \quad$ is the fraction of $K_{t}$ used in the goods-producing sector

$\left(1-a_{H}\right) \quad$ is the fraction of $H_{t}$ used in the goods-producing sector

$\left(1-a_{L}\right) \quad$ is the fraction of $L_{t}$ used in the goods-producing sector

Note that the use of technology in one instance does not preclude the simultaneous use of the same technology by another agent. In other words, technology has the characteristic of being is non-rival, and hence the entire existing level of technology $(A)$ is used in both sectors $^{2,3}$.

Output in time $t$ is given by:

$$
Y_{t}=\left[\left(1-a_{K}\right) K_{t}\right]^{\alpha}\left[\left(1-a_{H}\right) H_{t}\right]^{\beta}\left[A_{t}\left(1-a_{L}\right) L_{t}\right]^{1-\alpha-\beta}, \quad 0<\alpha<1,0<\beta<1, \alpha+\beta<1
$$

The level of innovation in the economy depends on the amount of capital, labor and human capital devoted to the R\&D sector and on the current level of technology. For this model, we assume a generalized Cobb-Douglas production function for the $R \& D$ sector.

\footnotetext{
${ }^{2}$ We therefore assume that there is zero excludability associated with technology in this economy.

${ }^{3}$ Although the acquisition of human capital by a worker involves learning, there is a clear conceptual distinction between human capital and disembodied knowledge in the form of technology. Human capital consists of the abilities, skills, knowledge and experience of particular workers. Thus, like conventional economic goods, human capital is rival and excludable. For example, if an engineer's full effort is being devoted to one activity, it precludes the use of his or her skills in another. In contrast, if an algorithm is being used in one activity, that in no way makes its use in another more difficult or less productive. (Romer 1996)
} 


$$
\dot{A}_{t}=B\left(a_{K} K_{t}\right)^{a}\left(a_{H} H_{t}\right)^{b}\left(a_{L} L_{t}\right)^{c} A_{t}^{\theta}, \quad B>0, a \geq 0, b \geq 0, c \geq 0, \theta \geq 0
$$

As in the Solow model, the savings rate is exogenous and constant. Also, we set depreciation to be zero for simplicity. This implies that the rate of capital accumulation or investment will be given by:

$$
\dot{K}_{t}=s_{K} Y_{t}, \quad 0 \leq s_{K} \leq 1
$$

We treat population growth and human capital growth to be constant and exogenous.

$$
\begin{array}{ll}
\dot{L}_{t}=n L_{t}, & n \geq 0 \\
\dot{H}_{t}=m H_{t}, & m \geq 0
\end{array}
$$

where $\dot{X}_{t} \equiv \frac{\partial X_{t}}{\partial t}$

Note that there are two state variables, $K_{t}$ and $A_{t}$, and that in steady state, all growth rates are constant.

\subsection{Derivation of the Steady-State Condition for Capital Accumulation}

To derive the steady-state condition for the capital $(K)$ accumulation, we first substitute (1) into (3) and we get,

$$
\begin{aligned}
& \dot{K}_{t}=s_{K}\left[\left(1-a_{K}\right) K_{t}\right]^{\alpha}\left[\left(1-a_{H}\right) H_{t}\right]^{\beta}\left[A_{t}\left(1-a_{L}\right) L_{t}\right]^{1-\alpha-\beta} \\
& =s_{K}\left(1-a_{K}\right)^{\alpha}\left(1-a_{H}\right)^{\beta}\left(1-a_{L}\right)^{1-\alpha-\beta} K_{t}^{\alpha} H_{t}^{\beta} A_{t}^{1-\alpha-\beta} L_{t}^{1-\alpha-\beta}
\end{aligned}
$$

Let $g_{K t}$ be the growth rate of $K_{t}$, hence

$$
g_{K t} \equiv \frac{\dot{K}_{t}}{K_{t}}=s_{K}\left(1-a_{K}\right)^{\alpha}\left(1-a_{H}\right)^{\beta}\left(1-a_{L}\right)^{1-\alpha-\beta} K_{t}^{\alpha-1} H_{t}^{\beta} A_{t}^{1-\alpha-\beta} L_{t}^{1-\alpha-\beta}
$$


Letting $c_{K} \equiv s_{K}\left(1-a_{K}\right)^{\alpha}\left(1-a_{H}\right)^{\beta}\left(1-a_{L}\right)^{1-\alpha-\beta}$, we get

$$
\begin{array}{rlrl}
g_{K t} & = & c_{K} K_{t}^{\alpha-1} H_{t}^{\beta} A_{t}^{1-\alpha-\beta} L_{t}^{1-\alpha-\beta} \\
& =\quad c_{K} K_{t}^{\alpha-1} H_{t}^{\beta} A_{t}^{1-\alpha-\beta} L_{t}^{1-\alpha-\beta} K_{t}^{\beta} K_{t}^{-\beta} \\
& =\quad c_{K}\left(\frac{H_{t}}{K_{t}}\right)^{\beta}\left(\frac{A_{t} L_{t}}{K_{t}}\right)^{1-\alpha-\beta}
\end{array}
$$

Taking logs on both sides, we get

$$
\begin{aligned}
\ln g_{K t} & =\ln \left[c_{K}\left(\frac{H_{t}}{K_{t}}\right)^{\beta}\left(\frac{A_{t} L_{t}}{K_{t}}\right)^{1-\alpha-\beta}\right] \\
& =\quad \ln c_{K}+\beta \ln \left(\frac{H_{t}}{K_{t}}\right)+(1-\alpha-\beta) \ln \left(\frac{A_{t} L_{t}}{K_{t}}\right)
\end{aligned}
$$

Taking differential with respect to time, we get

$$
\begin{aligned}
\dot{g}_{K t} \equiv \frac{\partial\left(\ln g_{K t}\right)}{\partial t} \quad & =\beta\left(\frac{1}{H_{t}} \frac{\partial H_{t}}{\partial t}-\frac{1}{K_{t}} \frac{\partial K_{t}}{\partial t}\right)+(1-\alpha-\beta)\left(\frac{1}{A_{t}} \frac{\partial A_{t}}{\partial t}+\frac{1}{L_{t}} \frac{\partial L_{t}}{\partial t}-\frac{1}{K_{t}} \frac{\partial K_{t}}{\partial t}\right) \\
& =\beta\left(g_{H t}-g_{K t}\right)+(1-\alpha-\beta)\left(g_{A t}+g_{L t}-g_{K t}\right) \\
& =\beta\left(m-g_{K t}\right)+(1-\alpha-\beta)\left(g_{A t}+n-g_{K t}\right)
\end{aligned}
$$

For the steady-state condition, we set $\dot{g}_{K t}=0$ resulting in

$\beta\left(m-g_{K}^{*}\right)+(1-\alpha-\beta)\left(g_{A}^{*}+n-g_{K}^{*}\right)=0$

with rearranging, we get

$$
g_{K}^{*} \quad=\quad\left(\frac{1-\alpha-\beta}{1-\alpha}\right) n+\left(\frac{1-\alpha-\beta}{1-\alpha}\right) g_{A}^{*}+\left(\frac{\beta}{1-\alpha}\right) m
$$


Recall it was assumed that $0<\alpha<1,0<\beta<1, \alpha+\beta<1$. Hence, the coefficient of $g_{A}$ will be $0<\left(\frac{1-\alpha-\beta}{1-\alpha}\right)<1$. Figure 1 illustrates the phase diagram with the locus of points where $\dot{g}_{K}=0$.

To see the dynamics around the locus $\dot{g}_{K}=0$, suppose that initially $g_{K}>g_{K}^{*}$, then from (7) we can see that $\dot{g}_{K}<0$. This implies that $g_{K}$ will decrease until $g_{K}=g_{K}^{*}$. Graphically, this corresponds to all points that are above the $\dot{g}_{K}=0$ locus will have a tendency to converge downwards to the $\dot{g}_{K}=0$ locus. Alternatively, suppose that $g_{K}<g_{K}^{*}$, then from (7) we can see that $\dot{g}_{K}>0$. This implies that $g_{K}$ will increase until $g_{K}=g_{K}^{*}$. Graphically, this corresponds to all points that are below the $\dot{g}_{K}=0$ locus will have a tendency to converge upwards to the $\dot{g}_{K}=0$ locus.

\subsection{Derivation of the Steady-State Condition for Technological Growth}

To derive the steady-state condition for technological growth $(A)$, recall from $(2)$ that

$$
\dot{A}_{t} \quad=\quad B\left(a_{K} K_{t}\right)^{a}\left(a_{H} H_{t}\right)^{b}\left(a_{L} L_{t}\right)^{c} A_{t}^{\theta}, \quad B>0, a \geq 0, b \geq 0, c \geq 0
$$

Let $g_{A t}$ be the growth rate of $A_{t}$, hence

$$
\begin{aligned}
g_{A t} \equiv \frac{\dot{A}_{t}}{A_{t}} & =\quad B\left(a_{K} K_{t}\right)^{a}\left(a_{H} H_{t}\right)^{b}\left(a_{L} L_{t}\right)^{c} A_{t}^{\theta-1} \\
& =\quad B a_{K}^{a} a_{H}^{b} a_{L}^{c} K_{t}^{a} H_{t}^{b} L_{t}^{c} A_{t}^{\theta-1}
\end{aligned}
$$

Letting $c_{A} \equiv B a_{K}^{a} a_{H}^{b} a_{L}^{c}$, we get

$$
g_{A t} \quad=\quad c_{A} K_{t}^{a} H_{t}^{b} L_{t}^{c} A_{t}^{\theta-1}
$$

Taking logs, we get

$\ln g_{A t}=\quad \ln c_{A}+a \ln K_{t}+b \ln H_{t}+c \ln L_{t}+(\theta-1) \ln A_{t}$ 
Taking differential with respect to time, we get

$$
\begin{aligned}
\dot{g}_{A t} \equiv \frac{\partial\left(\ln g_{A t}\right)}{\partial t} \quad & a \frac{1}{K_{t}} \frac{\partial K_{t}}{\partial t}+b \frac{1}{H_{t}} \frac{\partial H_{t}}{\partial t}+c \frac{1}{L_{t}} \frac{\partial L_{t}}{\partial t}+(\theta-1) \frac{1}{A_{t}} \frac{\partial A_{t}}{\partial t} \\
& =a g_{K t}+b g_{H t}+c g_{L t}+(\theta-1) g_{A t} \\
& =a g_{K t}+b m+c n+(\theta-1) g_{A t}
\end{aligned}
$$

For the steady-state condition, we set $\dot{g}_{A t}=0$ resulting in

$$
a g_{K}^{*}+b m+c n+(\theta-1) g_{A}^{*}=0
$$

Upon rearranging, we get

$$
g_{A}^{*} \quad=\quad \frac{a g_{K}^{*}+b m+c n}{1-\theta}
$$

or equivalently,

$$
g_{K}^{*} \quad=\quad-\frac{b}{a} m-\frac{c}{a} n+\left(\frac{1-\theta}{a}\right) g_{A}^{*}
$$

It will be seen later that in order for the existence of a steady-state solution, we will need to assume that $0 \leq \theta<1$. This implies that the slope of the $\dot{g}_{A}=0$ locus will be strictly positive. Figure 2 illustrates the phase diagram with the locus of points where $\dot{g}_{A}=0$, assuming $0 \leq \theta<1$.

To see the dynamics around the locus $\dot{g}_{A}=0$, suppose that initially $g_{A}>g_{A}^{*}$, then from (9) we can see that $\dot{g}_{A}<0$. This implies that $g_{A}$ will decrease until $g_{A}=g_{A}^{*}$. Graphically, this corresponds to all points that are to the right of the $\dot{g}_{A}=0$ locus will have a tendency to converge leftwards to the $\dot{g}_{A}=0$ locus. Alternatively, suppose that $g_{A}<g_{A}^{*}$, then from (9) we can see that $\dot{g}_{A}>0$. This implies that $g_{A}$ will increase until $g_{A}=g_{A}^{*}$. Graphically, this corresponds to all points that are to the left of the $\dot{g}_{A}=0$ locus will have a tendency to converge rightwards to the $\dot{g}_{A}=0$ locus. 


\subsection{Derivation of the Steady-State Solution}

To summarize, we have 2 equations representing steady-state conditions with 2 unknowns:

From setting $\dot{g}_{K t}=0$

$$
g_{K}^{*} \quad=\quad\left(\frac{1-\alpha-\beta}{1-\alpha}\right) n+\left(\frac{1-\alpha-\beta}{1-\alpha}\right) g_{A}^{*}+\left(\frac{\beta}{1-\alpha}\right) m
$$

From setting $\dot{g}_{A t}=0$

$$
g_{K}^{*} \quad=\quad-\frac{b}{a} m-\frac{c}{a} n+\left(\frac{1-\theta}{a}\right) g_{A}^{*}
$$

To find the intersection of the two steady-state conditions, we equate (8) and (10b)

$$
\left(\frac{1-\alpha-\beta}{1-\alpha}\right) n+\left(\frac{1-\alpha-\beta}{1-\alpha}\right) g_{A}^{*}+\left(\frac{\beta}{1-\alpha}\right) m=-\frac{b}{a} m-\frac{c}{a} n+\left(\frac{1-\theta}{a}\right) g_{A}^{*}
$$

With rearranging, it can be shown that

$$
g_{A}^{*}=\frac{1}{\left(\frac{1-\theta}{a}\right)-\left(\frac{1-\alpha-\beta}{1-\alpha}\right)}\left[\left(\frac{\beta}{1-\alpha}+\frac{b}{a}\right) m+\left(\frac{1-\alpha-\beta}{1-\alpha}+\frac{c}{a}\right) n\right]
$$

Note that the denominator of RHS term in equation (11) characterizes the nature of the steady-state solution for this economy. More specifically, the existence of the steadystate solution hinges on the sign of $\left(\frac{1-\theta}{a}\right)-\left(\frac{1-\alpha-\beta}{1-\alpha}\right)$. We now examine the various possible scenarios. 
Case $1:\left(\frac{1-\theta}{a}\right)<\left(\frac{1-\alpha-\beta}{1-\alpha}\right)$

Firstly, note that because the $\dot{g}_{A}=0$ locus has a negative $g_{K}$ axis intercept, the starting point of the $\dot{g}_{A}=0$ locus will always be vertically below that of the $\dot{g}_{K}=0$ locus. Consequently, in this case when the slope of the $\dot{g}_{K}=0$ locus is steeper than that of the $\dot{g}_{A}=0$ locus, the two loci constantly diverge and hence there is no intersection. Figure 3 illustrates the phase diagram that plots the two steady-state conditions simultaneously in the $g_{K^{-}} g_{A}$ space. It can be seen that regardless of where the economy's initial point, it eventually enters the region between the two loci. Once this occurs, the growth rates of both $A$ and $K$, and hence the growth rate of output, increase continually. Consequently, the economy exhibits ever-increasing growth, and there is no tendency to converge to a steady-state solution.

Case 1a: $\left(\frac{1-\theta}{a}\right)<\left(\frac{1-\alpha-\beta}{1-\alpha}\right), \theta>1$

This scenario is a special version of Case 1, where the slope of the $\dot{g}_{K}=0$ locus is still steeper than that of the $\dot{g}_{A}=0$ locus, the only difference being that the $\dot{g}_{A}=0$ locus now exhibits a negative slope. The dynamics is identical to Case 1 in that the two loci are constantly diverging leading to the non-existence of an intersection between the two loci and the economy does not converge to a steady-state solution (Figure 4).

Case $2:\left(\frac{1-\theta}{a}\right)=\left(\frac{1-\alpha-\beta}{1-\alpha}\right)$

This case is again similar to that of Case 1. Here slope of the $\dot{g}_{K}=0$ locus is equal to that of the $\dot{g}_{A}=0$ locus, thus the two loci are parallel and again non-intersecting. Once again there is no tendency for the economy to converge to a steady-state solution (Figure 5).

Case 3: $\left(\frac{1-\theta}{a}\right)>\left(\frac{1-\alpha-\beta}{1-\alpha}\right)$

The final possibility is when slope of the $\dot{g}_{K}=0$ locus is less steep than that of the $\dot{g}_{A}=0$ locus, which is illustrated in Figure 6 . It can be seen that in this case, the two steady-state loci intersect at point $E$. In terms of the dynamics, it can be verified that 
regardless of the economy's initial point, there is a tendency for the economy to converge to point $E$. This implies that point $E$ is a steady-state solution for the economy.

In light of the above analysis of the various possible cases, it can be concluded that for the existence of a steady-state solution, the following condition must hold:

$$
\left(\frac{1-\theta}{a}\right)-\left(\frac{1-\alpha-\beta}{1-\alpha}\right)>0
$$

Given that $0<\frac{1-\alpha-\beta}{1-\alpha}<1$, equation (12) also implies that $\theta<1^{4}$.

\subsection{Effect of Growth of Human Capital on Steady-State Technological Growth}

With reference to (11), it can be seen that the steady-state growth rate of technology will be depend positively on the growth rate of human capital if the coefficient $\frac{\left(\frac{\beta}{1-\alpha}+\frac{b}{a}\right)}{\left(\frac{1-\theta}{a}\right)-\left(\frac{1-\alpha-\beta}{1-\alpha}\right)}$ is positive. We note that the numerator $\left(\frac{\beta}{1-\alpha}+\frac{b}{a}\right)$ is unambiguously positive. In addition, we have just shown that the denominator $\left(\frac{1-\theta}{a}\right)-\left(\frac{1-\alpha-\beta}{1-\alpha}\right)$ must be positive for a steady-state solution to exist. The ratio must therefore be positive.

In summary, the model shows that an increase in the growth rate of human capital leads to increases in the steady-state growth rate of technology.

\footnotetext{
${ }^{4}$ For this reason, the $\dot{g}_{A}=0$ locus has been plotted with a positive slope.
} 


\subsection{Derivation of Steady-State Output Growth}

We are ultimately interested in the steady-state growth rate of output or per capita output.

From (1) and upon rearranging, we get:

$Y_{t}=\left(1-a_{K}\right)^{\alpha}\left(1-a_{H}\right)^{\beta}\left(1-a_{L}\right)^{1-\alpha-\beta} K_{t}^{\alpha} H_{t}^{\beta} A_{t}^{1-\alpha-\beta} L_{t}^{1-\alpha-\beta}$

Taking logs on both sides, we get

$\ln Y_{t}=\ln \left(1-a_{K}\right)^{\alpha}\left(1-a_{H}\right)^{\beta}\left(1-a_{L}\right)^{1-\alpha-\beta}+$

$\alpha \ln K_{t}+\beta \ln H_{t}+(1-\alpha-\beta) \ln A_{t}+(1-\alpha-\beta) \ln L_{t}$

Taking differential with respect to time, we get

$$
\begin{array}{rlrl}
g_{Y t} \equiv \frac{\partial\left(\ln Y_{t}\right)}{\partial t} & = & \alpha \frac{1}{K_{t}} \frac{\partial K_{t}}{\partial t}+\beta \frac{1}{H_{t}} \frac{\partial H_{t}}{\partial t}+(1-\alpha-\beta) \frac{1}{A_{t}} \frac{\partial A_{t}}{\partial t}+(1-\alpha-\beta) \frac{1}{L_{t}} \frac{\partial L_{t}}{\partial t} \\
& =\quad \alpha g_{K t}+\beta g_{H t}+(1-\alpha-\beta) g_{A t}+(1-\alpha-\beta) g_{L t} \\
& = & \alpha g_{K t}+\beta m+(1-\alpha-\beta) g_{A t}+(1-\alpha-\beta) n
\end{array}
$$

For steady-state output growth, we first substitute (8) into (13) and get:

$$
\begin{aligned}
g_{Y}^{*}=\quad & \alpha\left[\left(\frac{1-\alpha-\beta}{1-\alpha}\right) n+\left(\frac{1-\alpha-\beta}{1-\alpha}\right) g_{A}^{*}+\left(\frac{\beta}{1-\alpha}\right) m\right]+\beta m+ \\
& (1-\alpha-\beta) g_{A}^{*}+(1-\alpha-\beta) n
\end{aligned}
$$

With rearranging, (14) can be simplified to

$$
g_{Y}^{*} \quad=\quad \frac{1}{1-\alpha}\left[(1-\alpha-\beta) n+\beta m+(1-\alpha-\beta) g_{A}^{*}\right]
$$


Next, we substitute (11) into (15)

$$
\begin{aligned}
g_{Y}^{*}= & \frac{1}{1-\alpha}[(1-\alpha-\beta) n+\beta m]+ \\
& \frac{\frac{1}{1-\alpha}(1-\alpha-\beta)}{\left(\frac{1-\theta}{a}\right)-\left(\frac{1-\alpha-\beta}{1-\alpha}\right)}\left[\left(\frac{\beta}{1-\alpha}+\frac{b}{a}\right) m+\left(\frac{1-\alpha-\beta}{1-\alpha}+\frac{c}{a}\right) n\right]
\end{aligned}
$$

Upon simplifying, we get

$$
g_{Y}^{*}=\frac{[\beta(1-\theta)+b(1-\alpha-\beta)] m+(1-\alpha-\beta)(1-\theta+c) n}{(1-\theta)(1-\alpha)-a(1-\alpha-\beta)}
$$

Note that the condition for the existence of a steady-state solution (12) implies that the denominator of the RHS term of (16) is positive:

$$
\begin{aligned}
& \left(\frac{1-\theta}{a}\right)-\left(\frac{1-\alpha-\beta}{1-\alpha}\right) \quad>\quad 0 \\
& \Rightarrow \quad \frac{(1-\theta)(1-\alpha)-a(1-\alpha-\beta)}{a(1-\alpha)}>0 \\
& \Rightarrow \quad(1-\theta)(1-\alpha)-a(1-\alpha-\beta) \quad>\quad 0
\end{aligned}
$$

We are able to arrive at the expression immediately above because we know that $a(1-\alpha)>0$.

Thus, we see that coefficient of $m$ is positive, implying that increases in the growth rate of human capital leads to increases in the steady-state growth rate of output.

Similarly, in terms of steady-state per capita output growth:

$$
\begin{aligned}
g_{Y}^{*}-n & =\frac{[\beta(1-\theta)+b(1-\alpha-\beta)] m+(1-\alpha-\beta)(1-\theta+c) n}{(1-\theta)(1-\alpha)-a(1-\alpha-\beta)}-n \\
& =\frac{[\beta(1-\theta)+b(1-\alpha-\beta)]}{(1-\theta)(1-\alpha)-a(1-\alpha-\beta)} m+\left[\frac{(1-\alpha-\beta)(1-\theta+c)}{(1-\theta)(1-\alpha)-a(1-\alpha-\beta)}-1\right] n
\end{aligned}
$$


Thus increases in the growth rate of human capital also lead to increases in the steadystate growth rate of output per capita.

\section{Policy Exercises}

In this section, we consider the steady-state effects of two scenarios that could result from common development-oriented policies. The first exercise focuses on education and considers an exogenous increase in the rate of human capital accumulation, which could result from the country experiencing a one-time increase in the number of new schools. In the second scenario, we examine the role of information and communications technology (ICT) in economic development, by assuming an exogenous one-time increase or improvement in the economy's ICT infrastructure. Both exercises show that even one-time positive shocks can have long-run effects on technological growth, capital accumulation and economic development.

\subsection{An Increase in the Growth Rate of Human Capital Accumulation}

Consider an exogenous increase in the growth rate of human capital accumulation (from $m^{0}$ to $m^{l}$ ). With reference to Figure 7 , it can be seen that this decreases the intercept of the $\dot{g}_{A}=0$ locus, and consequently, resulting in a parallel downward shift from $\left(\dot{g}_{A}=0\right)^{0}$ to $\left(\dot{g}_{A}=0\right)^{1}$. At the same time, the increase in the growth rate of human capital accumulation increases the intercept of the $\dot{g}_{K}=0$ locus, and consequently, leads to an upward parallel shift from $\left(\dot{g}_{K}=0\right)^{0}$ to $\left(\dot{g}_{K}=0\right)^{1}$. As a result, the steady-state solution for the economy moved from $E^{0}$ to $E^{l}$, with the steady-state growth rate of technology increasing from $g_{A}^{* 0}$ to $g_{A}^{* 1}$, and the steady-state growth rate of capital increasing from $g_{K}^{* 0}$ to $g_{K}^{* 1}$.

Intuitively, the increase in the growth rate human capital first results in a larger stock of human capital in the economy. Assuming that the share of human capital being allocated to the R\&D sector remains unchanged, the increase in human capital in the R\&D sector leads to more innovations and discoveries, which results in the increase in the growth rate of technology, from $g_{A}^{* 0}$ to $g_{A}^{*{ }_{1}}$. The larger growth rate of the human capital also simultaneously increases the amount of resources being used in the conventional goods-producing sector. In this sector, the larger growth rate of the human capital stock, together with the more rapid level of technological growth (resulting from the R\&D sector), leads to an increase in the growth rate of output. Given that a fixed 
proportion of output is invested as new capital, the rate of capital accumulation also increases with the increased rate of output production, which results in the increase from $g_{K}^{*_{0}}$ to $g_{K}^{*_{1}}$. To summarize, an exogenous increase in the growth rate of human capital in our model increases the long-term growth rate of technology, capital and output.

\subsection{An Improvement in the ICT Infrastructure}

Information and communications technologies (ICTs) are the backbone of the knowledge economy and in recent years have been recognized as an effective tool for promoting economic growth and sustainable development. With relatively low usage costs and the ability to overcome distance, ICTs have revolutionized the transfer of information, knowledge and technology around the world.

ICT infrastructure in an economy refers to the accessibility, reliability and efficiency of computers, phones, television and radio sets, and the various networks that link them. The World Bank Group defines ICT to consist of hardware, software, networks, and media for collection, storage, processing transmission, and presentation of information in the form of voice, data, text, and images. They range from the telephone, radio and television to the Internet (World Bank, 2003a and 2003b).

Over the past decade, there has been a series of studies that show that both ICT production and ICT usage have contributed to economic growth ${ }^{5}$. One of the most obvious benefits associated with ICT usage is the increased flow of information and knowledge. Because ICTs allow information to be transmitted relatively inexpensively and efficiently, ICT usage increases the flow of information, technology and knowledge, and hence technologies can be acquired and adapted more easily leading to increased innovation and productivity.

In light of the above, we argue that an improvement or an increase in the level of the economy's ICT infrastructure increases the efficiency of which the existing level of technology contributes to the production of innovation and discoveries. More specifically, an improvement in the ICT infrastructure will increase $\theta^{6}$. Figure 8 illustrates the effect of an exogenous improvement in the ICT infrastructure on our two-

\footnotetext{
${ }^{5}$ See Chen and Dahlman (2004), Pilat and Lee (2001), Jorgenson and Stiroh (2000), Oliner and Sichel (2000), Whelan (2000), and Schreyer (2000).

${ }^{6}$ ICT usage has also been cited to increase the rate of human capital accumulation because ICTs tend to increase the access to existing knowledge and information (see World Bank, 2003a and 2003b). Given that the case of an increase in the rate of human capital accumulation has been analyzed above, we will focus here exclusively on the positive effect of ICTs on the contribution of existing technology to innovation output.
} 
sector economy via an increase in the value of $\theta$. As $\theta$ increases from $\theta^{0}$ to $\theta^{1}$, the slope of the $\dot{g}_{A}=0$ locus becomes more gentle leading to the clockwise pivot of the locus from $\left(\dot{g}_{A}=0\right)^{0}$ to $\left(\dot{g}_{A}=0\right)^{1}$. This results in the steady-state solution of the economy to move from $E^{0}$ to $E^{l}$, and the steady-state growth rate of technology to increase from $g_{A}^{*_{0}}$ to $g_{A}^{*_{1}}$, and the steady-state growth rate of capital to increase from $g_{K}^{*_{0}}$ to $g_{K}^{* 1}$.

Intuitively, the increased flow of information and knowledge, resulting from the improvement in the ICT infrastructure, allows innovation to be produced more efficiently, holding constant the level of existing technology. This increase in efficiency increases the steady-state growth rate of technology, resulting in the increase from $g_{A}^{* 0}$ to $g_{A}^{*_{1}}$. Subsequently, the increase in the steady-state growth rate of technology increases the steady-state growth rate of output, which leads to the increase in the steady-state growth rate of capital, resulting in the increase from $g_{K}^{* 0}$ to $g_{K}^{*_{1}} \cdot 7$

\section{Summary and Conclusion}

The first generation of endogenous growth models, such as Romer (1990), predict that the long-run growth rate of an economy is proportionate to the level of resources devoted to R\&D, such as the stock of human capital. Such scale effects are not consistent with the growth experience of the East Asia NIEs and many industrialized countries. This issue of scale effects was addressed by the second generation of endogenous growth models, such as Jones (1995). However, along with the scale effects, the latter class of models also removed any channels via which government policies could influence the long-term growth rate of per capita income.

In this paper, we have developed an endogenous growth model that relates the long-run growth rate of an economy to the growth of human capital. This is consistent with the growth experience of the East Asia NIEs, where education and schooling have improved tremendously in a short period of time, even though the overall stock of human capital is still lacking behind the industrialized countries. Furthermore, this model reintroduces the possibility of steady-state growth effects via government intervention - by affecting the growth rate of human capital.

\footnotetext{
${ }^{7}$ Note that the effect of the improvement in the ICT infrastructure differs from the increase in the growth rate of human capital accumulation in that in the former only the locus moved, whereas in the latter, we observed shifts in both of the steady-state loci. The key reason for this difference lies in the number of sectors being initially affected by the shocks. The ICT improvement initially affects the R\&D sector and permeates the economy only through the R\&D sector. In the human capital growth rate exercise, the increase in the growth rate of human capital leads to a larger stock of human capital that simultaneously enters both output and R\&D sectors, resulting in the movement of both steady-state loci.
} 


\section{References:}

Aghion, Philippe and Peter Howitt (1992). "A Model of Growth Through Creative Destruction.” Econometrica. Vol. 60, No. 2 (March), pp. 323-351.

Aghion, Philippe and Peter Howitt (1998). Endogenous Growth Theory. MIT Press.

Barro, Robert J. (1991). "Economic Growth in a Cross-Section of Countries." Quarterly Journal of Economics. Vol. 106, No. 2, pp. 407-443.

Chen, Derek H. C. and Carl J. Dahlman (2004). "Knowledge and Development: A Cross-Section Approach." World Bank Policy Research Working Paper No. 3366. The World Bank, Washington D.C., August.

Dinopoulos, Elias and Peter Thompson (1998). "Schumpeterian Growth without Scale Effects.” Journal of Economic Growth. Vol. 3, No. 4 (December), pp. 313-335.

Grossman, Gene and Elhanan Helpman (1991). Innovation and Growth in the Global Economy. MIT Press.

Hall, Robert E. and Charles I. Jones (1999). "Why Do Some Countries Produce So Much More Output per Worker than Others ?" Quarterly Journal of Economics. Vol. 114, February, pp. 83-116.

Howitt, Peter and Philippe Aghion (1998). "Capital Accumulation and Innovation as Complementary Factors in Long-Run Growth." Journal of Economic Growth. Vol. 3 (June), pp. 111-130.

Jones, Charles I. (1995). "R\&D-Based Models of Economic Growth.” Journal of Political Economy. Vol. 103, No. 4 (August), pp. 759-784.

Jones, Charles I. (1999). “Growth: With or Without Scale Effects?” American Economic Review. Vol. 89, No. 2 (May), pp. 139-144.

Jorgenson, Dale W. and Kevin Stiroh (2000). "Raising the Speed Limit: U.S. Economic Growth in the Information Age." Brookings Papers on Economic Activity. Vol. 1, pp. 125-211.

Kortum, Samuel (1997). "Research, Patenting and Technological Change." Econometrica. Vol. 65, No. 6, pp. 1389-1419.

Krueger, Allan B. and Mikael Lindahl (2000). "Education for Growth: Why and For Whom?" National Bureau of Economic Research Working Paper No. 7591. 
Lederman, Daniel and William F. Maloney (2003). "R\&D and Development." Policy Research Working Paper No. 3024, The World Bank.

Lloyd-Ellis, Huw and Joanne Roberts (2002). "Twin Engines of Growth: Skills and Technology as Equal Partners in Balanced Growth." Journal of Economic Growth. Vol. 7, pp. 87-115.

Mankiw, N. Gregory, David Romer and David N. Weil (1992). "A Contribution to the Empirics of Economic Growth." Quarterly Journal of Economics. Vol. 107, No. 2 (May), pp. 407-437.

Oliner, Stephen D. and Sichel, Daniel E. (2000). "The Resurgence of Growth in the Late 1990s: Is Information Technology the Story?" Journal of Economic Perspectives. Vol. 14, No. 4 (Fall), pp. 3-22.

Peretto, Pietro (1998). "Technological Change and Population Growth.” Journal of Economic Growth. Vol. 3, No. 4 (December), pp. 283-311.

Pilat, Dirk and Frank C. Lee (2001). "Productivity Growth in ICT producing and ICT-Using Industries: A Source of Growth Differentials in the OECD?" STI Working Paper 2001/4, Organisation for Economic Co-operation and Development.

Romer, David (1996). Advanced Macroeconomics. McGraw Hill.

Romer, Paul M. (1990). "Endogenous Technological Change." Journal of Political Economy. Vol. 98, No. 5, Pt. 2, pp. S71-102.

Schreyer, Paul (2000). "The Contribution of Information and Communication Technology to Output Growth: A Study of the G7 Countries." STI Working Paper 2000/2, Organisation for Economic Co-operation and Development, Paris.

Segerstrom, Paul (1998). "Endogenous Growth without Scale Effects." American Economic Review. Vol. 88, No. 5 (December), pp. 1290-1310.

Segerstrom, Paul (1998). "The Long-Run Growth Effects of R\&D Subsidies." Journal of Economic Growth. Vol. 5 (September), pp. 277-305.

Temple, Jonathan (1999). "The New Growth Evidence." Journal of Economic Literature. Vol. 37, March, pp. 112-156.

Whelan, Karl (2000). "Computers, Obsolescence, and Productivity." Finance and Economics Discussion Series. 2000-6, Federal Reserve Board, Washington, DC.

World Bank (2003a). Engendering ICT: Ensuring Gender Equality in ICT for Development. Washington, D.C., September. 
World Bank (2003b). ICT and MDGs: A World Bank Group Perspective. Washington, D.C., December.

Young, Alwyn (1998). "Growth without Scale Effects." Journal of Political Economy. Vol. 106, No. 1 (February), pp. 41-63. 
Figure 1: Phase Diagram for the Dynamics of the Growth Rate of Capital

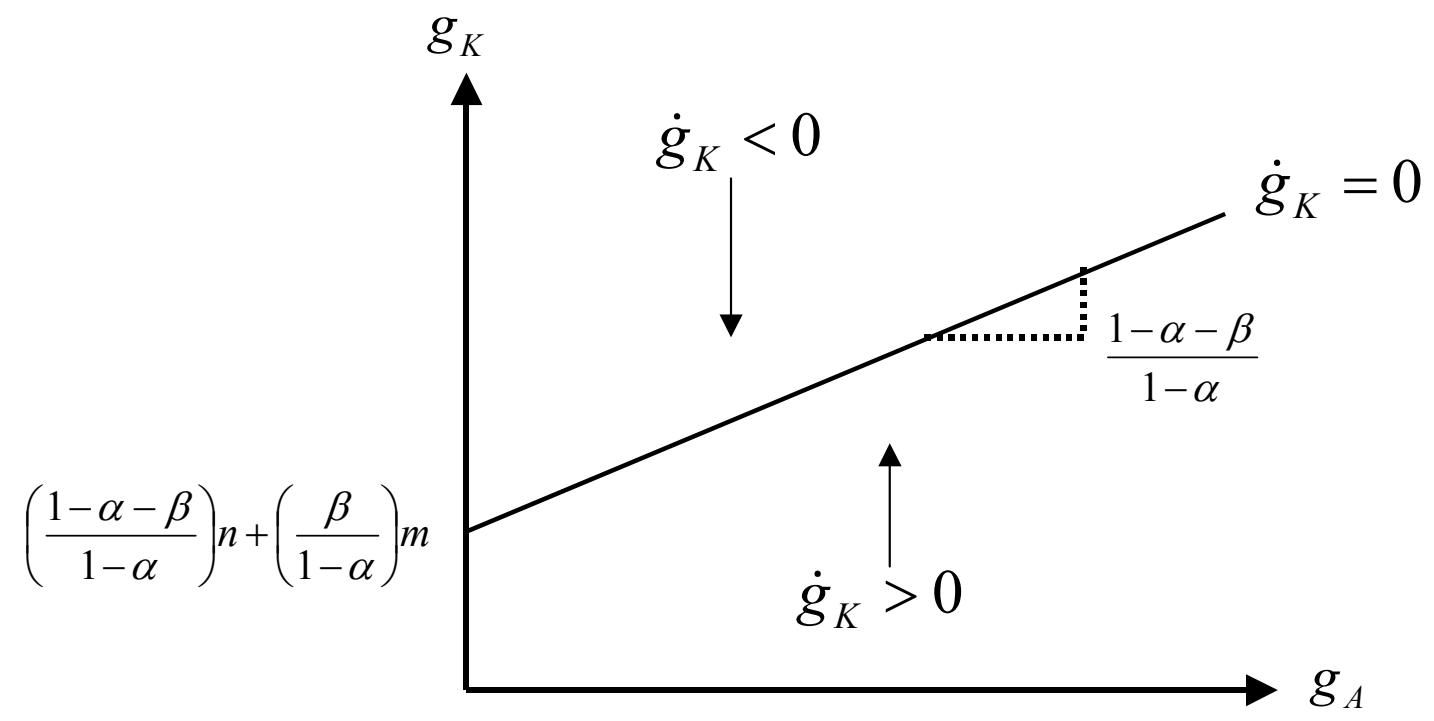

Figure 2: Phase Diagram for the Dynamics of the Growth Rate of Knowledge

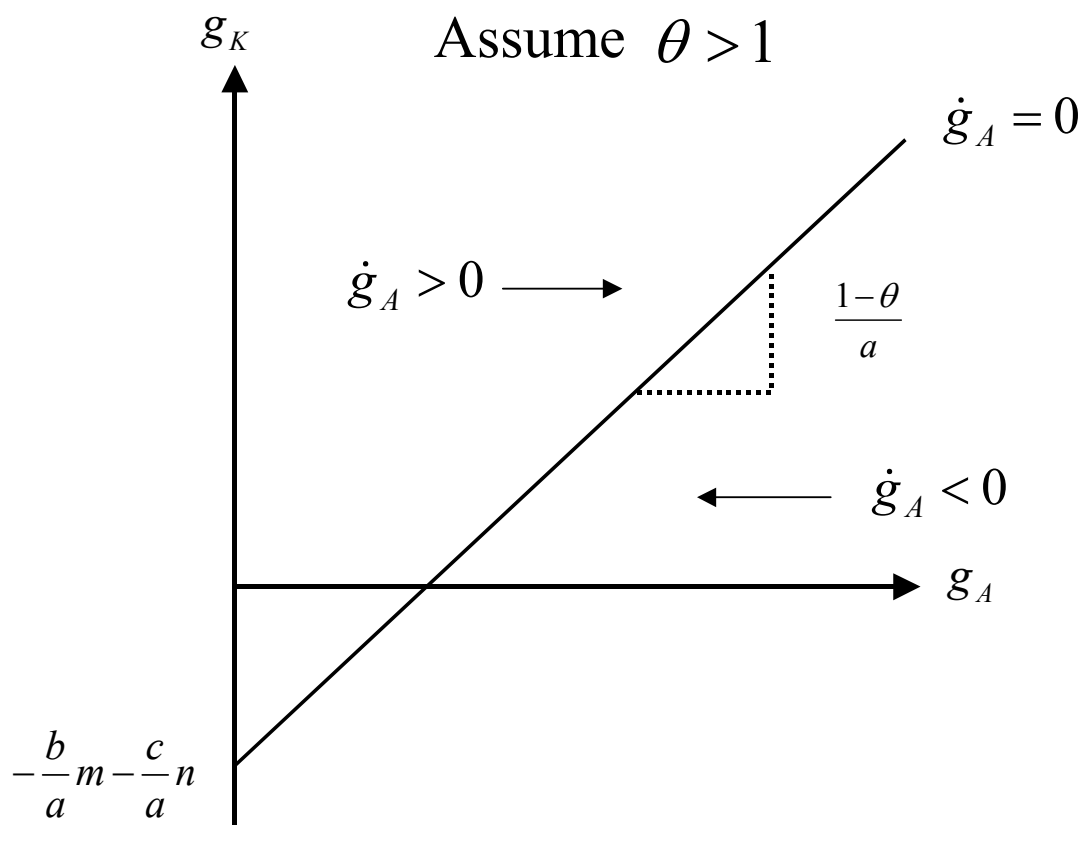


Figure 3: Phase Diagram for the Dynamics of the Growth Rate of Capital and Knowledge

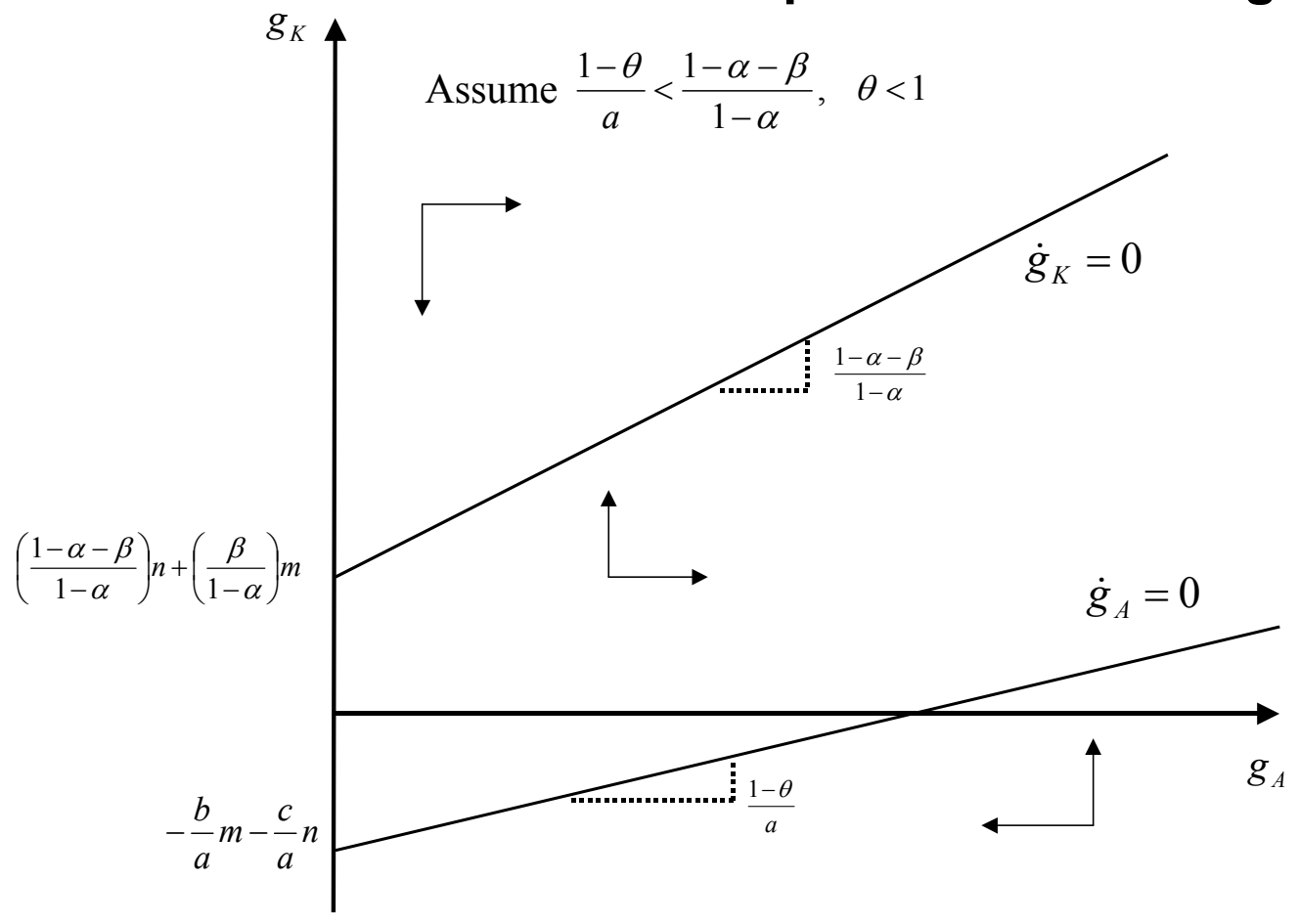

Figure 4: Phase Diagram for the Dynamics of the Growth Rate of Capital and Knowledge

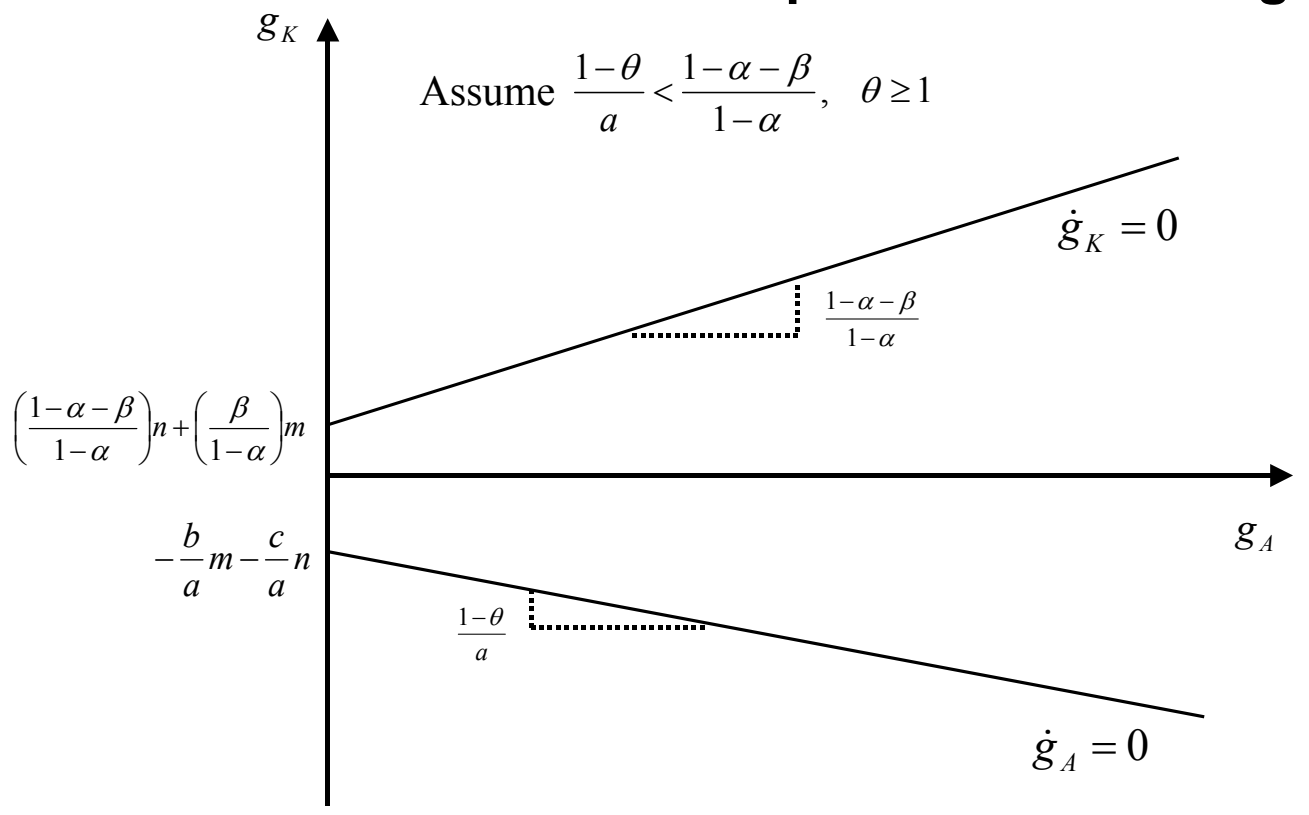


Figure 5: Phase Diagram for the Dynamics of the Growth Rate of Capital and Knowledge

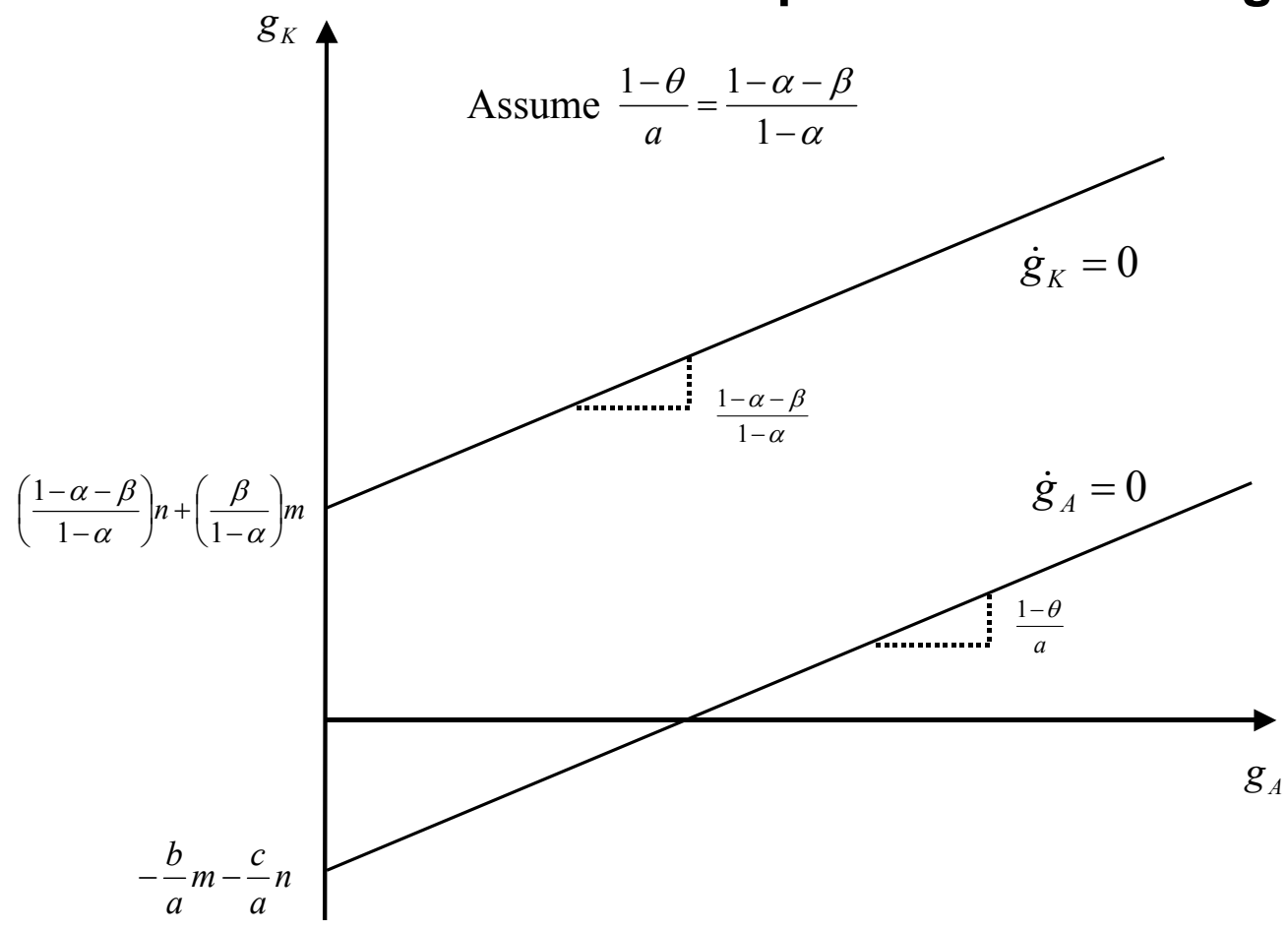

Figure 6: Phase Diagram for the Dynamics of the Growth Rate of Capital and Knowledge

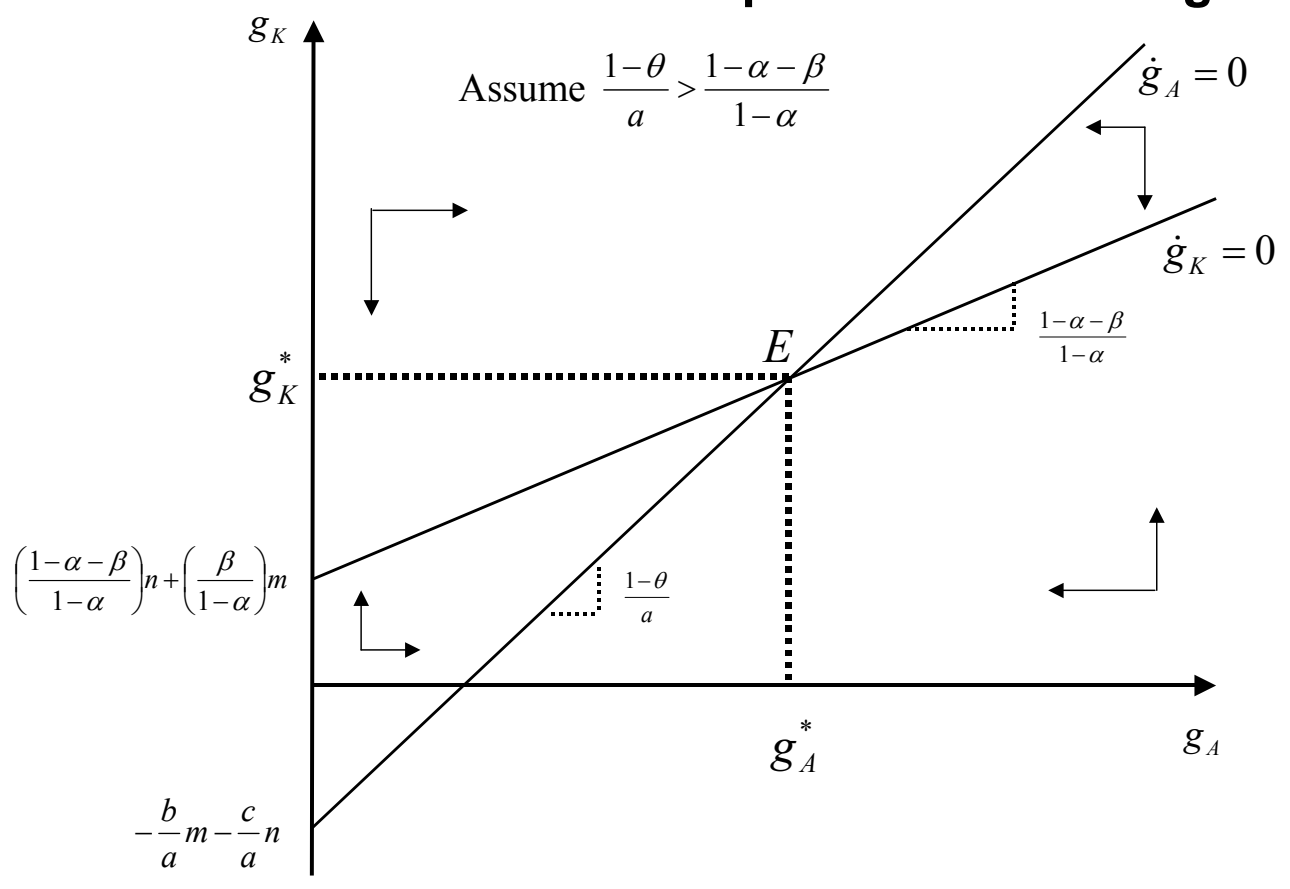


Figure 7: An Increase in the Growth Rate of Human Capital Accumulation

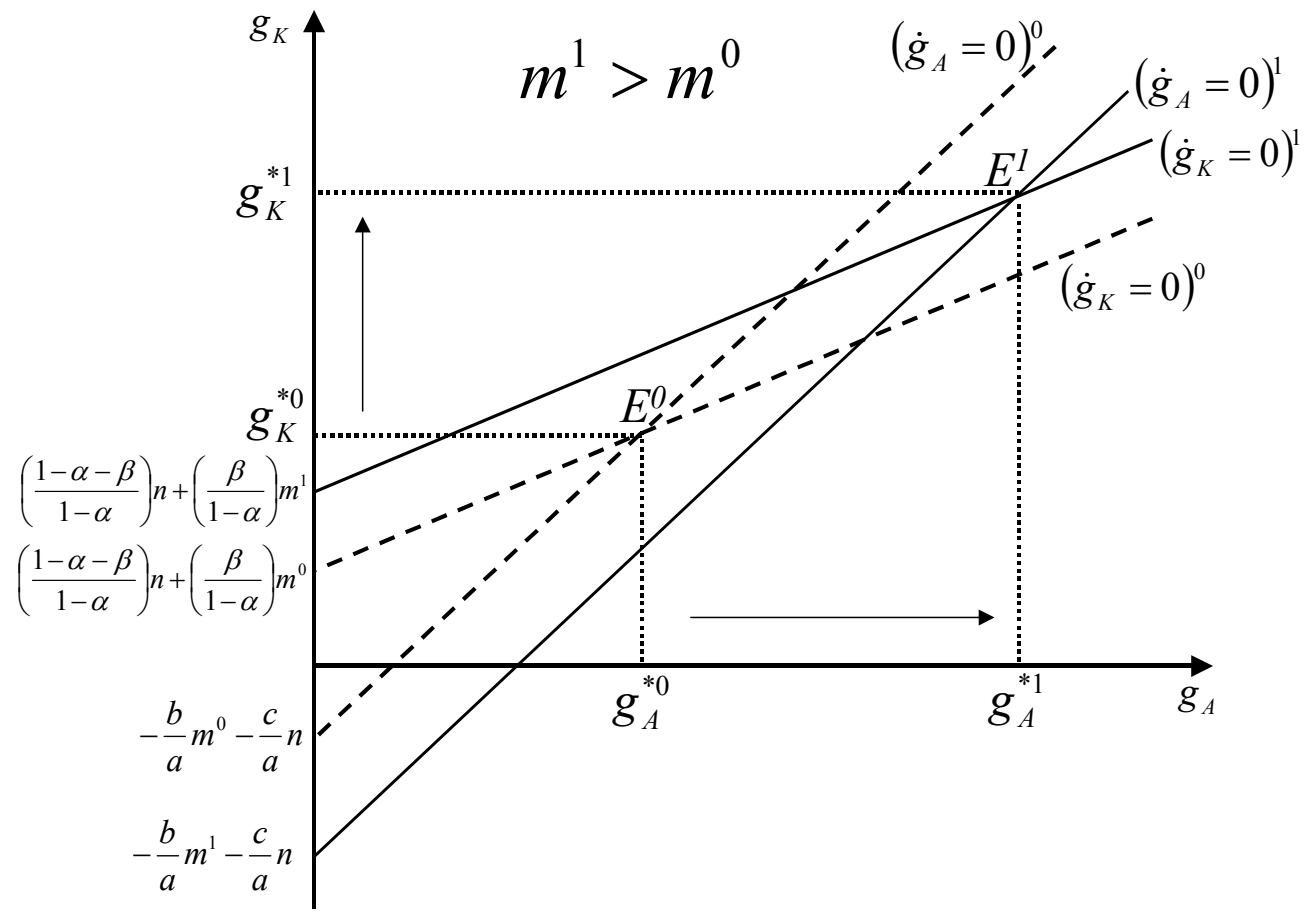

Figure 8: An Improvement in the ICT Infrastructure $\theta^{1}>\theta^{0}$

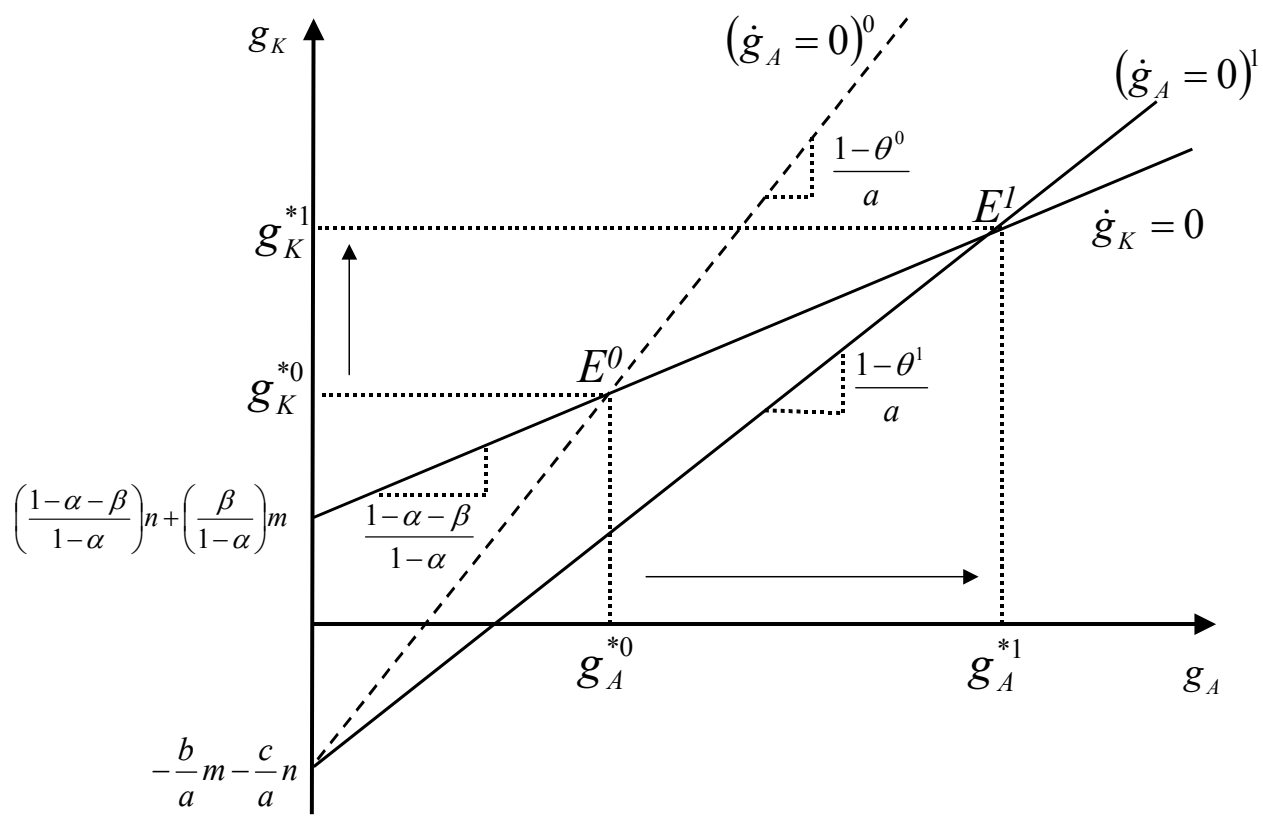

